\title{
PERCEPÇÕES SOBRE O TOQUE ENFERMEIRA E PACIENTE VISÃO DOS ALUNOS DE GRADUAÇÃO DE ENFERMAGEM
}

Maria Julia Paes da Silva* Maguida Costa Stefanelli**

SILVA, M.J.P. da; STEFANELLI, M.C. Percepçōes sobre o toque enfermeira e paciente: visão dos alunos de graduação. Rev.Esc.Enf.USP, v.28, n.3, p.270-80, dez. 1994.

Por considerar o toque um dos sinais nào verbais mais importantes na relaçào enfermeira-paciente, as autoras passaram a ensinar durante o curso de graduaçào de enfermagem, um bloco teórico, com aplicação teórico-prática sobre comunicação nào verbal, incluindo conceitos gerais do tocar. Este trabalho teve como objetivos verificar como os alunos, após terem passado pelo bloco teórico citado, estavam percebendo a maneira das enfermeiras tocarem os pacientes durante a assistência de enfermagem, como eles tomam a decisão de tocar as pacientes que estāo sob seus cuidados e, quando, segundo a percepção dos alunos, o toque pode ser considerado uma experiência positiva ou uma experiência negativa para o paciente. Dentre os dados obtidos, após questionário aplicado a 32 alunos, verificou-se que a maioria das vezes a enfermeira toca o paciente, segundo os alunos, para a execuçào do exame fisico, ou seja, é um toque instrumental.

UNITERMOS: Comunicaçāo nāo verbal. Toque.

\section{INTRODUÇÃO}

De 4 anos para cá, introduziu-se uma nova sistematização no ensino da comunicação enfermeira-paciente abordando aspectos da comunicação não verbal. Isso aconteceu, após uma docente da disciplina que introduz o aluno no hospital, no cuidado com os pacientes, considerar que mesmo já ministrando o assunto "comunicaçāo enfermeiro-paciente" no seu conteúdo programático, a comunicação não verbal merecia ser mais enfatizada. É vital a importância desta na compreensão correta das mensagens enviadas pelos pacientes ${ }^{10}$.

Entre os tipos de sinais não verbais abordados, o toque é um deles, por ser de fundamental importância que a enfermeira o perceba como parte integrante do cuidado de enfermagem. Que currículos ou disciplinas de enfermagem ainda falam de medidas de conforto, massoterapia, mecânica

\footnotetext{
- Enfermeira. Professor Doutor do Departamento de Enfermagem da Universidade de São Paulo.

* Professor Titular do Departamento de Enfermagem Materno-Infantil e Psiquiátrica da Escola de Enfermagem da Universidade de Såo Paulo.
} 
postural e auto-conhecimento como embasamento fundamental para o cuidar da enfermeira?

Ao se abordar, nessa disciplina, os aspectos não verbais da comunicação são discutidos conceitos gerais do "tocar", como: $1^{\text {o) }}$ a pele como sendo o órgão que primeiro interpreta o mundo para o ser humano, pois as primeiras experiências de exploração do mundo ocorrem através desta; $2^{\circ}$ ) o toque como comunicação não verbal, abordando todas as características que o envolvem, como pressão exercida, local onde se toca, idade e sexo dos comunicadores, entre outros aspectos, envolvidos no tocar: privacidade, consentimento da pessoa "tocada", espaço pessoal e territoriedade, diferenças individuais e culturais.

É feita também uma diferença entre o toque instrumental - aquele que requer contato físico deliberado para que a enfermeira execute alguma atividade como: colocar termômetro, verificar pulso, fazer curativo, por exemplo; e, o toque afetivo - que é espontâneo e tem a finalidade de demonstrar empatia, apoio, segurança e proximidade para com o paciente ${ }^{9}$.

Nossa preocupação em abordar esse tipo de comunicação não verbal junto aos alunos existe porque aceitamos que o toque é parte indissociável do cuidar em enfermagem e, talvez, em alguns casos, a maneira mais rápida de se estabelecer a relação com o paciente para que surjam confiança, empatia e encorajamento, eliminando-se, portanto, as defesas do paciente para a livre expressão de seus sentimentos e pensamentos.

\section{REVISÃO BIBLIOGRÁFICA}

GODOY ${ }^{3}$, afirma que, a julgar pela ausência de publicações em língua portuguesa sobre o tocar, poder-se-ia pensar que, na assistência de enfermagem, o toque não é valorizado como elemento componente do cuidado. Questiona como assistir a um outro ser, como profissional de enfermagem, sem tocá-lo. A autora citada conclui, a partir de seu levantamento bibliográfico, que $o$ toque e o cuidado são inseparáveis, devendo o aquele fazer parte do plano de cuidados do cliente. Comenta que além de ser um recurso eficaz na interação enfermeira-cliente, o toque é considerado, também, uma intervenção do profissional de enfermagem e um meio de cura.

Concordamos com a autora e ainda ressaltamos que, em algumas ocasiōes, o toque significa cuidado.

WEISS $^{12}$ afirma que a linguagem do toque pode ser analisada segundo os seguintes símbolos: duração, localização (áreas mais sensíveis, mais externas, mais próximas do coração); ação ou a velocidade com que um se aproxima do outro (abrupto, gradual); intensidade ou a pressão exercida no outro; freqüência e sensação provocada - a reação de conforto ou desconforto na pele ao receber ou transmitir o estímulo.

Um grande número de estudos é citado por MONTAGU ${ }^{8}$ mostrando a importância do tocar, desde pesquisas relacionando determinados tipos de asma a uma falta de estimulação tátil no início da vida, até o desejo de engravidar e maior número de toques entre mães e seus recém-nascidos, entre outros. 
HENLEY ${ }^{4}$ fez um estudo em 1977 mostrando que é mais provável que a pessoa toque a outra quando estiver dando uma informaçāo ou uma ordem; pedindo um favor; tentando convencer; numa conversa informal, em festas; quando excitada. Por outro lado, é mais provável que ela não toque o outro quando estiver pedindo uma informação, recebendo uma ordem, consentindo em fazer um favor, sendo convencida de algo, numa conversa casual, no trabalho, entre outros.

BARNETT' ${ }^{1}$, já em 1972, observou que as enfermeiras tocam mais os pacientes adultos jovens do que os velhos, alertando para que as pessoas de terceira idade têm a necessidade de continuarem sendo tocadas.

Em 1974,McCORKLE ${ }^{7}$ percebeu ser mais freqüente encontrar expressões faciais positivas, ou seja, as que demonstram alegria, satisfação, calma, entre outras, nos pacientes gravemente enfermos tocados afetivamente pelo pessoal de enfermagem, do que em pacientes só tocados em momentos "técnicos", quando ocorre a execução de algum procedimento.

$\mathrm{LYNCH}^{6}$, em 1978 , já afirmou que quanto mais traumático for o meio ambiente de um paciente, mais ele precisa ser "tocado". Ele estudou o ritmo cardíaco de pacientes em unidades de recuperação cardíaca e choque, antes e após interações com familiares, enfermeiros e médicos. Verificou que em pacientes cardíacos, o toque sempre provocava uma alteração no ritmo cardíaco, e que este ritmo, poderia ser diminuído com o simples ato da enfermeira ficar segurando-lhes a mão. $O$ autor considera que muitas outras variáveis precisam ser controladas para se chegar a resultados mais precisos. Entre estas, cita a idade dos pacientes, patologia cardíaca, entre outras, mas garante que apesar desses fatores, podemos observar os efeitos do toque entre os seres humanos.

Visto que o significado percebido do toque varia de acordo com a parte do corpo tocada, o tempo de duração desse contato, a pressão aplicada, o modo de tocar como, por exemplo, mão espalmada ou fechada, a freqüência com que ele ocorre ${ }^{8,9,12}$ e, preocupadas com a formação da futura enfermeira, consideramos pertinente verificar como os alunos do último ano do curso de graduação em enfermagem estão percebendo essa maneira de interação entre enfermeira e paciente. $O$ estudo tem como finalidade obter subsídios para a adequação do ensino do tema.

\section{OBJETIVOS}

No presente trabalho temos como objetivos verificar:

- como os alunos estão percebendo o toque na comunicação enfermeira-paciente durante a assistência de enfermagem;

- quando o toque é considerado uma experiência positiva ou uma experiência negativa para o paciente, segundo a percepção dos alunos;

- como os alunos tomam a decisão de tocar os pacientes que estão sob seus cuidados. 
População

A população desse estudo constou de 32 alunos do $7^{\circ}$ semestre do curso de graduação em enfermagem do ano de 1992, que estavam presentes nas salas de aula no dia da coleta de dados, cursando as disciplinas de Enfermagem Psiquiátrica ou Enfermagem em Saúde Coletiva.

Os alunos conheciam os objetivos do estudo, estavam cientes que a participação nessa pesquisa era facultativa, e que seu anonimato seria preservado.

\section{Procedimento}

Os dados foram colhidos por uma das autoras do trabalho, em março de 1992, através da aplicação do questionário anexo. Os alunos tiveram 30 minutos para responder as questões sobre quando as enfermeiras tocam 0 paciente, que tipos de toque foi possível ser observado entre ambos e que partes do corpo do paciente são tocadas com mais frequiência. Também lhes foi solicitada a opinião sobre quando 0 toque pode ser uma experiência positiva e uma experiência negativa para o paciente e, como eles decidiam quando e onde tocar os pacientes.

\section{DISCUSSÃO DOS RESULTADOS}

Pelas respostas obtidas pudemos identificar que, na opinião dos alunos, as enfermeiras tocam os pacientes em diversas situações que são apresentadas na Tabela 1.

TABELA 1. Situações em que ocorre o toque entre enfermeira e paciente, segundo a percepção dos alunos de graduação. São Paulo, 1992.

\begin{tabular}{lr}
\hline SITUAÇȮES & $\mathrm{N}^{*}$ \\
\hline Durante execução de procedimentos & 3 \\
\hline Durante exame físico & 19 \\
\hline Raramente tocam & 18 \\
\hline Com paciente que precisa apoio ou consolo & 4 \\
\hline Com paciente com dor & 2 \\
\hline Com paciente queixoso & 2 \\
\hline Com paciente agitado & 19 \\
\hline *Total & 49 \\
\hline (*) O total corresponde ao número de respostas apresentadas e náo ao nummero total de alunos, porque alguns \\
deles especificaram mais de uma situaçăo.
\end{tabular}


Pela Tabela 1 podemos observar que a maioria das citações está relacionada a toques instrumentais ${ }^{22}$, ou seja, aqueles que requerem um contato físico deliberado para que a enfermeira execute alguma atividade ${ }^{9}$; houve, também, um alto número de citações (18) afirmando que as enfermeiras raramente tocam seus pacientes.

É contínuo o desafio às enfermeiras para decidirem quando e onde tocar seus pacientes. Todos nós, seres humanos, precisamos ser tocados e essa necessidade aumenta quando ficamos doentes ${ }^{1.7 .8}$. As enfermeiras têm de decidir se vão usar o toque indiscriminadamente, intuitivamente ou se vão tomar por base algum conhecimento, ensinamento ou planejamento. O tocar está muito ligado a sensação de "estar próximo", de "envolver-se" com alguém. Decidir tocar espontaneamente outra pessoa implica também em se expor, pois o ato do toque é bilateral, há sempre alguma troca entre as pessoas.

Além do que, a enfermeira sempre recebe uma resposta não verbal ao tocar o paciente.

Acreditamos que os cuidados diários de enfermagem, como banho, massagear as costas, posicionar no leito, dar medicação, verificar os sinais vitais oferecem oportunidades para um toque firme e confortante, aliando o fazer técnico ao expressivo, com a demonstração de atenção, apoio e envolvimento emocional.

Os resultados da pergunta sobre o tipo de toque que os alunos puderam observar entre enfermeira e paciente foram agrupados segundo a linguagem utilizada pelos alunos e suas respostas estão expostas na Tabela 2.

TABELA 2. Tipos de toque entre enfermeira-paciente observados pelos alunos. Săo Paulo, 1992.

\begin{tabular}{lr}
\hline TIPOS & $N^{*}$ \\
\hline Toque instrumental & 15 \\
\hline Toque afetivo & 12 \\
\hline Toques rápidos/bruscos & 6 \\
\hline Para aliviar a dor & 3 \\
\hline Toque terapêutico & 1 \\
\hline Sem colocar a mảo toda & 1 \\
\hline Não responderam & 4 \\
\hline *Total & 42 \\
\hline
\end{tabular}

(*) O total corresponde ao número de respostas apresentadas e nào ao número total de alunos. porque alguns deles especificaram mais de uma situaçäo

Na Tabela 2 podemos observar que ainda é o toque instrumental que aparece na maior parte das citações e, das 12 vezes em que é citado o toque afetivo, em 6 deles os alunos referiram que ele foi observado raramente. Dentre essas 12 citaçōes, 2 referiram ter observado o toque afetivo em 
paciente terminal. Um dos alunos faz referência ao "toque terapêutico", porém não explica com que conotação esse termo foi utilizado e também não descreve o toque observado. Não foi observado esclarecer se a denominação do toque era pertinente à finalidade com que foi usado ou se a usada por KRIEGER $^{5}$. Não consideramos que ele se refira ao toque afetivo, porque esse mesmo aluno cita o toque afetivo separadamente.

Os segmentos do corpo dos pacientes tocados com maior frequêencia pelas enfermeiras, segundo a percep̧̧ão dos alunos de graduação, estão relacionados na Tabela 3.

TABELA 3. Segmentos do corpo do paciente mais tocados pelas enfermeiras, segundo a percepção dos alunos de graduação. São Paulo, 1992.

\begin{tabular}{lr}
\hline SEGMENTOS & N $^{0}$ de citaçỏes \\
\hline MMSS (Membros Superiores) & 23 \\
\hline Mãos & 12 \\
\hline Cabeça & 8 \\
\hline MMII (Membros Inferiores) & 6 \\
\hline Abdome & 5 \\
\hline Rosto & 4 \\
\hline Outros & 3 \\
\hline Total & 61 \\
\hline
\end{tabular}

(*) $\mathrm{O}$ total corresponde ao número de respostas apresentadas e não ao número total de alunos, porque alguns deles especificaram mais de uma situaçăo

Podemos verificar que são os MMSS e mãos os locais mais citados pelos alunos. VORTHERMS ${ }^{11}$ refere que para os idosos, os locais mais confortáveis de serem tocados são as mãos, braços e ombros, pois qualquer outro local do corpo pode ser considerado inapropriado por eles. A autora não generaliza esses dados para pessoas de todas as idades.

Muitos dos procedimentos "rotineiros" no atendimento do paciente hospitalizado envolvem tocá-los principalmente nos MMSS e mãos: verificar sinais vitais, ministrar medicações e soros, auxílio para a locomoção, entre outros.

VORTHERMS11 também alerta para a importância dos docentes de enfermagem criarem situaçōes onde se possa discutir o uso do toque como tipo de comunicação não verbal e estimular o desenvolvimento do conhecimento de referenciais para o uso positivo do toque nos pacientes pelos alunos. É necessário encorajá-los a observar o que o toque provoca em diferentes situações e o quanto as relações podem se tornar mais empáticas a partir dele.

A percepção dos alunos sobre quando o toque pode ser uma experiência positiva para os pacientes é apresentada na Tabela 4. 
TABELA 4. Situação em que o toque foi percebido como experiência ponitiva para os pacientes, segundo os alunos de graduaçăo. Săo Paulo, 1992.

\begin{tabular}{lc}
\hline SITUAÇĀO & No \\
\hline Paciente angustiado/ansioso & 14 \\
\hline Oferecimento de dar apoio & 14 \\
\hline Na demonstração de interesse pela pessoa & 12 \\
\hline Paciente com medo & 8 \\
\hline Estabelecimento de vínculo de confiança & 7 \\
\hline Paciente com dor & 5 \\
\hline No preparo de paciente para procedimentos & 4 \\
\hline Quando é respeitada sua privacidade & 3 \\
\hline Quando năo é violento & 3 \\
\hline $\begin{array}{l}\text { Paciente estar impedido que não pode } \\
\text { verbalizar }\end{array}$ & 2 \\
\hline $\begin{array}{l}\text { Quando a enf tem sentimentos positivos } \\
\text { sobre o paciente }\end{array}$ & 2 \\
\hline Solicitaçảo do paciente & 1 \\
\hline Total & 75 \\
\hline
\end{tabular}

(*) $\mathrm{O}$ total corresponde ao número de respostas apresentadas e não ao número total de alunos, porque alguns deles especificaram mais de uma situação

Podemos verificar que o maior número de citações se refere ao uso do toque como positivo para pacientes ansiosos ou com medo e para se demonstrar apoio e interesse. Esses dados encontram respaldo nos achados de BRADY $^{2}$ e GODOY ${ }^{3}$, que indicam o uso do toque para pacientes que se sentem solitários, com dor, em fase terminal, ansiosos, tristes, que estão sendo submetidos a uma realidade cruel, com perda de auto-estima, com deficiência sensorial ou motora. Lembram que o toque pode transmitir confiança, apoio e atenção, mas que a enfermeira precisa usar o bom senso e não se esquecer do estilo de vida e cultura de cada paciente.

$\mathrm{Na}$ Tabela 5 podemos verificar a percepção dos alunos sobre quando o toque pode ser uma experiência negativa para os pacientes.

TABELA 6. Situaçð̃e em que o toque foi percebido como experiência negativa para os pacientes, segundo os alunos de graduação. São Paulo, 1992

\begin{tabular}{lr}
\hline SITUAÇŌES & $N^{*}$ \\
\hline Na execuçáo de procedimentos sem consentimento do paciente & 15 \\
\hline Quando não corresponde às expectativas do paciente & 15 \\
\hline Quando é só técnico - sem a fetividade & 8 \\
\hline Quando a enfermeira estar com expressảo facial "negativa" & 8 \\
\hline Quando é procedimetno ou local dolorido & 4 \\
\hline Quando o toque é brusco & 4 \\
\hline (*) Total & 54 \\
\hline
\end{tabular}

(*) $\mathrm{O}$ total corresponde ao número de respostas apresentadas e nảo ao número total de alunos, porque alguns deles especificaram mais de uma situação 
Aproximadamente $50 \%$ dos alunos (15) lembraram que quando tocamos alguém estamos invadindo seu território (o espaço ao nosso redor considerado como "nosso") e, portanto, precisamos estar atentas aos sinais nāo verbais que demonstram o "consentimento" do paciente com relação a essa invasão do seu espaço pessoal ou territoriedade, como, por exemplo, sua expressão facial, rigidez muscular, direção do olhar, entre outros ${ }^{10}$.

Foram 15 citaçōes mencionando idade, cultura, experiência anterior, como fatores que alteram as expectativas dos pacientes quanto ao toque $\mathrm{e}, \mathrm{a}$ necessidade do paciente também entender o motivo de estar sendo tocado, 0 que é encontrado também na literatura ${ }^{3,4.8}$.

Foi lembrado ( 8 vezes) que quando executamos um procedimento, só por ele mesmo, enquanto técnica, podemos transmitir ao paciente falta de interesses pela pessoa, tornando negativo esse contato.

Essas citações feitas pelos alunos também dizem respeito ao fato de as enfermeiras executarem os procedimentos com uma expressão facial "negativa" (8 citações), pois o sentimento que a enfermeira transmite para o paciente é um conjunto, uma somatória dos sinais não verbais emitidos por seu corpo e sua postura ${ }^{10}$.

Houve apenas uma citação afirmando que o toque nunca é negativo. Se aceitamos que existem diferenças individuais de idade, sexo, cultura, experiência prévia, não podemos aceitar essa afirmação ou, pelo menos, aceitá-la com restrições, corroborando nossa experiência e a literatura existente ${ }^{2,3,11}$.

Como os alunos decidem quando e onde tocar os pacientes, as justificativas que originam sua tomada de decisão quanto ao tocar podem ser observadas na Tabela 6.

TABELA 6. Motivos da tomada de decisão dos alunos sobre tocar os pacientes. São Paulo, 1992.

\begin{tabular}{lr}
\hline MOTIVOS & tocar os pacientes. São Paulo, 1992. \\
\hline Observação & $N^{0}$ \\
\hline Observando o náo verbal do paciente & 13 \\
\hline Quando quer demonstrar apoiolinteresse & 13 \\
\hline Se já houve aproximação prévia & 9 \\
\hline Depende da empatia, de estar envolvida & 7 \\
\hline Quando é possível resguardar a privacidade & 7 \\
do paciente & 6 \\
\hline Para tranquilizá-lo & 5 \\
\hline Quando estão com dor & 3 \\
\hline Quando o paciente pede & 3 \\
\hline Para cumprimentá-lo & 2 \\
\hline Em casos graves & 1 \\
\hline No exame físico & 1 \\
\hline (*) Total & 70 \\
\hline
\end{tabular}

(*) $O$ total corresponde ao número de respostas apresentadas e não ao número total de alunos, porque alguns deles especificaram mais de uma situação.

Pela Tabela 6 podemos verificar a existência do "bom senso" quando os alunos afirmam que é observando o paciente que se percebe a necessidade do 
toque ( 13 citações) e, apesar de existirem outras 13 citaçōes registrando que essa decisão de tocar é tomada segundo a percep̧̧ão do não verbal do paciente, consideramos que essas 26 citaçōes estão bastante relacionadas, pois quando se observa um paciente, também se observa seu comportamento não verbal.

Vemos aqui, que os alunos passam, na maior parte das citações, a considerar o toque como afetivo, isto é, aquele que é espontâneo e não tem finalidade "técnica", aparentemente sem perceber que é realmente com esse tipo de toque que podemos escolher o momento e o local para torná-lo realmente terapêutico, desvinculando-o de procedimentos que exijam o contato físico. Eles lembram que o toque pode existir quando já houve aproximação prévia ( 7 citaçōes), se a enfermeira está envolvida com o paciente ( 7 citaçōes), quando querem demonstrar apoio, interesse, tranquilizá-lo, entre outros.

BRADY $^{2}$, GODOY ${ }^{3}$, PEARCE $^{9}$, entre outros, são autoras que validaram, em pesquisas, os motivos citados pelos alunos como propulsores do ato de tocar afetivamente os pacientes. Afirmam que é só nos lembrarmos dos momentos em que nos sentimos apoiados, "cuidados" para verificarmos 0 quanto o toque esteve presente nessas situaçōes.

É importante ressaltar que 10 alunos afirmaram que costumam tocar os pacientes principalmente nas mãos e MMSS, por considerarem estas regiōes como áreas em que normalmente não se invade a privacidade do paciente e é a mais aceita para ser exposta e tocada na nossa cultura.

\section{CONCLUSŌES}

Com base nos dados obtidos nesse trabalho pudemos concluir que os alunos consideram que as enfermeiras ao cuidarem dos pacientes, nos hospitais campo de estudo, estão usando principalmente o toque instrumental e, que esse tipo de toque ocorre, na maior parte das vezes, nos MMSS e mãos dos pacientes.

$\mathrm{Na}$ compreensão dos alunos, o toque foi considerado uma experiência positiva para os pacientes quando ocorreu para dar apoio, transmitir confiança, diminuir sua angústia, medo ou dor, entre outros. Foi considerado como experiência negativa para os pacientes quando ocorreu sem o consentimento do mesmo, quando o paciente não entendeu o porquê dele estar ocorrendo, quando foi só "técnico", sem expressar a afetividade da enfermeira.

Os alunos decidem tocar os pacientes que estão sob seus cuidados a partir da observação do próprio paciente, do seu comportamento não verbal e quando querem transmitir apoio, interesse, tranquilidade. Lembram que para tocar afetivamente um paciente é necessário que tenha havido aproximação anterior da enfermeira e, que ela esteja envolvida e seja capaz de desenvolver empatia na relação entre ambos.

As autoras consideram que as respostas dos alunos demonstram que estão atentos à importância do toque como cuidado na relação com os pacientes, o que está de acordo com a bibliografia consultada e oferecem respaldo 
para as autoras continuarem a pesquisar e a ensinar sobre o toque como elemento importante do cuidar em enfermagem. Consideramos fundamental que, nos processos de ensino-aprendizagem, se considere as percepções, opiniões e vivências dos alunos.

SILVA, M.J.P. da; STEFANELLI, M.C. The touch between nurses and patients: nursing students perception. Rev.Esc.Enf.USP, v.28, n.3, p.270-80 , dec. 1994.

The touch is considered by the author a important sign nonverbal in the nursew - patient relationship. The authors are teaching in the nursing undergraduate a systematic approach about nonverbal communication, including the touch.

The perception of the students after this knowledge are discussed in this paper and also when the touch may be a positive or negative experience to patients. The results of the 32 questionnaries administered to nursing students shows that the nurses are using the functional touch mainly.

UNITERMS: Communicacion nonverbal. Touch.

\section{REFERÊNCIAS BIBLIOGRÁFICAS}

1. BARNETT, $K$. A theorethical construct of concepts of touch as they relate to nursing. Nurs.Res., v.21, n.2, p. 102-10, 1972.

2. BRADY, B.A. Using the right touch. Nursing, v.21, n.5, p.46-7, 1991.

3. GODOY, A.N. O toque como parte da ação no processo de relacionamento enfermeiro-paciente. Rio de Janeiro, 1988, 142p. Tese(Livre-Docência) - Faculdade de Enfermagem, Universidade Estadual do Rio de Janeiro.

4. HENLEY, N.M. Body politics: power, sex and nonverbal communication. Englewood Chiffs, Prentice-Hall, 1977.

5. KRIEGER, D. The therapeutic touch: how to use your hands to help or the heal. New York. Prentice-Hall, 1979

6. LYNCH, J.J. The simple act of touching. Nursing, v.8, n.6, p. 32-6, 1978.

7. McCORKLE, R. The effects of touch on seriously ill patients. Nurs.Res., v.23, n.2, p. 125-32, 1974.

8. MONTAGU, A. Tocar: o significado humano da pele. São Paulo, Summus, 1988.

9. PEARCE,J. The power of touch. Nurs.Times, v.84, n.24, p.26-9, 1988.

10.SILVA, M.J.P. A percepção das enfermeiras sobre a comunicação não verbal dos pacientes. São Paulo, 1989. 113p. Dissertação (Mestrado) - Escola de Enfermagem, Universidade de São Paulo.

11. VORTHERMS, R.C. Clinically improving communication through touch. J.Gerontol.Nurs., v.17, n.5, p.6-9, 1991.

12. WEISS, S.J. The language of touch. Nurs.Res., v.28, n.2, p.76.80, 1979. 


\begin{abstract}
ANEXO I
QUESTIONÁRIO SOBRE O TOQUE ENFERMEIRA-PACIENTE

Por favor, responda todas as perguntas de maneira clara e não identifique a folha. As respostas devem ser embasadas na sua observação e experiência nos campos de estágio. Obrigada pela colaboração!

1. Quando as enfermeiras tocam o paciente?

2. Que tipos de toque você teve oportunidade de observar entre enfermeirapciente?

3. Onde (que partes do corpo) as enfermeiras tocam os pacientes com maior frequência?

4. Quando o toque pode ser uma experiência positiva para o paciente?

5. Quando o toque pode ser uma experiência negativa para o paciente?

6. Como você decide quando e onde tocar os pacientes?
\end{abstract}

